\title{
O PRINCÍPIO DO MELHOR INTERESSE DA CRIANÇA: UMA ANÁLISE À LUZ DO ORDENAMENTO JURÍDICO BRASILEIRO
}

\author{
THE PRINCIPLE OF THE BEST INTEREST OF THE CHILD: AN ANALYSIS UNDER \\ THE BRAZILIAN LEGAL SYSTEM
}

\author{
Bruna Aline Freire dos Santos ${ }^{1}$ \\ Aloísio Alencar Bolwerk ${ }^{2}$
}

\section{RESUMO}

A pesquisa visa a analisar a aplicação do princípio do melhor interesse da criança na legislação brasileira, por meio de estudo do cenário histórico e do enredo jurídico que abraça os sujeitos amparados pelo Estatuto da Criança e do Adolescente. O trabalho é lapidado a partir de discussão acerca das inovações legislativas nesse ramo do direito e tem por objetivo geral a defesa da evolução legislativa como ferramenta para a busca da proteção integral dos menores. Ademais, procurou também destacar o impacto de determinadas modificações legais e que foram capazes de reestruturar a roupagem jurídica e 0 arcabouço das tutelas resguardadas àqueles que são considerados vulneráveis em razão da condição de menoridade. O método dedutivo fora apresentado e contextualizado para desenvolver a evolução jurídica do Direito da Criança e do Adolescente no ordenamento brasileiro, assim como para apontar os avanços conquistados, principalmente quanto à conquista da crescente tutela protetiva a recepcionar e abastecer a seara legal dos menores de dezoito anos.

Palavras-chave: Direito da Criança e do Adolescente; Melhor Interesse da Criança; Legislação Brasileira.

\footnotetext{
1 E-mail: brunaaline@uft.edu.br. ORCID ID: https://orcid.org/0000-0001-7529-032X

${ }^{2}$ Doutorado em Direito Privado (com distinção magna cum laude) pela Pontifícia Universidade Católica de Minas Gerais. Mestre em Direitos Difusos e Coletivos pela Universidade Metropolitana de Santos. Possui graduação em Direito e estudos pós-graduados em Direito Público e Professor Adjunto da Fundação Universidade Federal do Tocantins. Professor Permanente do Programa de Mestrado Profissional em Prestação Jurisdicional e Direitos Humanos da UFT/ESMAT. Líder do Grupo de Pesquisa Hermenêutica Jurídica registrado no CNPQ. Advogado. E-mail: bolwerk@uft.edu.br ORCID ID: https://orcid.org/0000-0003-4229-4337
} 


\section{ABSTRACT}

The research aims to analyze the application of the principle of the best interest of the child in the Brazilian legislation, by means of a study of the historical context and the legal situation of the subjects protected by the Statute of Children and Adolescents. The work is developed starting from a discussion about the legislative innovations in this area of law and its main goal is to defend the legislative evolution as a tool in the search for the integral protection of the minors. Moreover, it also aimed to highlight the impact of certain legislative modifications that were able to change the legal structure and the framework of the legal protection dedicated to those who are vulnerable due to the minority. The deductive method was presented and contextualized to develop the legal evolution of the Children's and Adolescents' Rights on the Brazilian legal system, as well as pointing to the conquered advances, more importantly when it comes to the achievement of the growing protection that receives and supplies the legal area of the minors.

Keywords: Children's and Adolescents' Rights; Best Interest of the Child; Brazilian Legislation.

\section{INTRODUÇÃO}

O Direito da Criança e do Adolescente é um importante ramo da ciência jurídica, pois se dedica a sujeitos de direito que merecem proteção especial. Dentro desse ramo do Direito, destaca-se o princípio do melhor interesse da criança e do adolescente, que, como princípio basilar dessa área jurídica, deve orientar não só a atividade legislativa, como também as decisões judiciais que envolvam os menores de dezoito anos. Logo, em sua condição peculiar de pessoa em desenvolvimento, a criança e o adolescente necessitam de atenção especial do poder público.

Entretanto, os primeiros dispositivos legais que tratavam da criança e do adolescente no Brasil não garantiam uma proteção satisfatória, visto que se referiam apenas aos menores em situação irregular, sem tutelar direitos básicos a todas as crianças e adolescentes. Foi preciso uma profunda mudança legislativa, a qual sofreu influências de dispositivos internacionais e da própria Constituição Federal de 1988, para que o ordenamento jurídico brasileiro passasse a contar com leis específicas que atendessem às reais necessidades dos menores de dezoito anos.

Nesse sentido, o presente artigo tem como objetivo analisar os avanços da legislação brasileira em relação ao Direito da Criança e do Adolescente a partir do princípio do melhor interesse da criança, destacando sua importância e sua crescente 
presença nesse ramo do Direito. Dessa forma, busca-se apresentar uma evolução histórica dos direitos da criança e do adolescente no Brasil, debater sobre o princípio do melhor interesse da criança e analisar alguns dispositivos legais nos quais o princípio em destaque se faça presente.

O tema em questão é de grande relevância, visto que os estudos realizados no âmbito do Direito da Criança e do Adolescente influenciam diretamente o desenvolvimento de políticas públicas que visam a proteger a infância e a adolescência, de modo a garantir o sucesso do indivíduo em sua vida adulta.

Para o desenvolvimento desse estudo foi realizada uma pesquisa exploratória com a finalidade de compreender a principiologia do Direito da Criança e do Adolescente. $O$ método dedutivo fora empregado porque partiu da análise e da aplicação (subsunção) das leis do ordenamento aos casos que abraçam a tutela protetiva dos menores. Ademais, foi realizada pesquisa exploratória de natureza bibliográfica na doutrina especializada em consonância com a legislação pátria.

Sendo assim, fora apresentado o contexto histórico do Direito da Criança e do Adolescente no Brasil, seguido de uma análise do princípio do melhor interesse da criança e de sua aplicação na legislação brasileira.

\section{CONSIDERAÇÕES SOBRE A EVOLUÇÃO HISTÓRICA E OS PRINCÍPIOS NORTEADORES}

Até a promulgação do Estatuto da Criança e do Adolescente (ECA), não havia preocupação com os menores de idade de modo geral, apenas com o "menor em situação irregular", isto é, o menor abandonado e o menor infrator. Os principais instrumentos jurídicos dessa fase foram o Código de Menores de 1927 (também chamado de Código Mello Mattos ${ }^{3}$ ) e o novo Código de Menores de 1979, os quais abordavam, principalmente, medidas de repressão, sem definir direitos básicos para a criança e o adolescente.

3 "O código de Menores de 1927 ficou conhecido como Código Mello Mattos em alusão a José Cândido Albuquerque Mello Mattos, primeiro Juiz de Menores do Brasil e da América Latina, empossado em 2 de fevereiro de 1924" (SILVEIRA, 2015, p. 16). 
O Código de Menores de 1927, promulgado por meio do Decreto ํo 17.943-A, tratava, de acordo com seu art. $1^{\circ}$, do menor "abandonado ou delinquente" e procurava solucionar essa situação por meio da internação de tais crianças e adolescentes, sem atentar para suas reais necessidades (LIMA; VERONESE, 2012, p. 34-35).

As crianças e adolescentes pobres, ditos menores, não eram possuidores de direitos, eram considerados meros objetos e estavam à disposição do Estado, que representado no Poder Judiciário encontrou na internação a solução pedagógica para resolver os conflitos urbanos e o problema da criminalidade (LIMA; VERONESE, 2012, p. 33, grifo das autoras).

Prosseguindo nessa análise histórica, faz-se necessário citar, para efeitos de contextualização, a aprovação, pela Organização das Nações Unidas (ONU), da Declaração Universal dos Direitos da Criança, em 1959, a qual representou um avanço para o Direito da Criança e do Adolescente, visto que passou a determinar o menor de dezoito anos como sujeito de direitos.

Como signatário desse tratado, o Brasil teve a chance de colocar suas disposições em prática com a aprovação do novo Código de Menores (Lei № 6.697), em 1979. Porém, o novo Código não trouxe melhoras significativas à situação do menor, visto que adotou a Doutrina Jurídica da Situação Irregular $^{4}$ e somente aumentou o rol de menores que se enquadravam nessa situação, deixando a referida Declaração apenas no papel (LIMA; VERONESE, 2012, p. 38-43).

Outro elemento que deve ser citado por fazer parte dessa fase do Direito da Criança e do Adolescente é a Política Nacional do Bem-Estar do Menor (PNBEM), a qual surgiu com a aprovação da Lei no 4.513/64 e prevaleceu no Novo Código de Menores, conforme verificado em seu art. 4º I. A lei em questão autorizava, em seu art. 1ํㅡ, o Poder Executivo a instituir a Fundação Nacional do Bem-Estar do Menor (FUNABEM), que, de acordo com seu art. 5, tinha "como objetivo formular e implantar a política nacional do bem-estar do menor, mediante o estudo do problema e planejamento das soluções, a orientação, coordenação e fiscalização das entidades

\footnotetext{
4 "A doutrina jurídica da situação irregular passou a vigorar efetivamente entre nós com o advento do Código de Menores de 1979" (PEREIRA, 2000, p. 219, grifo da autora) e formalizava o fato de que o Código apenas se atentava aos menores em situação irregular, assim compreendidos aqueles que se enquadravam nas situações descritas no art. $2^{\circ}$ da Lei $n^{\circ}$ 6.697/79.
} 
que executem essa política" (BRASIL, 1964) ${ }^{5}$. Porém, "A PNBEM insistiu nas práticas de institucionalização como uma forma de promover a segurança social" (LIMA; VERONESE, 2012, p. 37).

Silveira (2015, p. 23) ressalta que, além da ineficácia das medidas previstas no Código de Menores, a internação era realizada sem qualquer distinção entre menores infratores, órfãos e abandonados, o que demonstra a falta de compromisso do Estado com a real proteção das crianças e dos adolescentes da época. "A intervenção estatal operava sem limites, de forma discricionária e ao arbítrio do juiz" (SILVEIRA, 2015, p. 23).

Ainda sobre o Código de Menores de 1979 e abordando a Doutrina Jurídica da Situação Irregular, Lima e Veronese explicam que:

[...] ficou estabelecido que o novo Código de Menores, enquanto instrumento normativo regulador do Direito do Menor, deveria se ocupar de tutelar apenas os menores emergenciais, ou seja, não se deveria ampliar a proteção e assistência àqueles que não necessitavam, pois estariam numa situação regular (LIMA; VERONESE, 2012, p. 41).

As mudanças começam a surgir com a Constituição Federal de 1988, a qual, revolucionária ao trazer um extenso rol de direitos fundamentais, não deixou de tutelar os direitos dos menores de dezoito anos, conforme verificado em seu art. 227:

Art. 227. É dever da família, da sociedade e do Estado assegurar à criança, ao adolescente e ao jovem, com absoluta prioridade, o direito à vida, à saúde, à alimentação, à educação, ao lazer, à profissionalização, à cultura, à dignidade, ao respeito, à liberdade e à convivência familiar e comunitária, além de colocálos a salvo de toda forma de negligência, discriminação, exploração, violência, crueldade e opressão (BRASIL, 1988).

Esse dispositivo é de extrema relevância, pois consagrou, no ordenamento jurídico brasileiro, a Doutrina da Proteção Integral (em contraposição à até então adotada Doutrina Jurídica da Situação Irregular), a qual "significa que, além de todos os direitos assegurados aos adultos, [...] as crianças e os adolescentes disporão de um plus, simbolizado pela completa e indisponível tutela estatal para lhes afirmar a vida digna e próspera [...]" ( $\mathrm{NUCCl}, 2014$, p. 26, grifo do autor). Logo, percebe-se uma

\footnotetext{
${ }^{5}$ A Lei no 4.513/64 também extinguiu, em seu art. 5ํㅡ, parágrafo único, o Serviço de Assistência a Menores (SAM), que era o órgão responsável, antes da criação da FUNABEM, por prestar atendimento assistencial aos menores em situação irregular.
} 
mudança no tratamento à criança e ao adolescente, já que a própria Lei Maior passa a determinar que todos os menores, e não apenas aqueles "em situação irregular", merecem a atenção de sua família, da sociedade em geral e do Estado.

Dessa forma, "pela necessidade de regulamentar o dispositivo 227 da Constituição da República Federativa do Brasil de 1988 e para contemplar numa lei específica a doutrina da proteção integral" (LIMA; VERONESE, 2012, p. 54), é aprovado, em 1990, o Estatuto da Criança e Adolescente (Lei o 8.069), reforçando esse novo olhar sobre os menores de dezoito anos.

Diferentemente dos Códigos de Menores que se destinavam ao menor abandonado ou em situação irregular, o Estatuto se aplica a toda e qualquer criança ou adolescente, impondo consequente e necessária interpretação de todas as normas relativas aos menores de idade à luz dos princípios ali estabelecidos (BARBOZA, p. 104, grifo da autora apud NUCCI, 2014, p. 27).

Também no ano de 1990 , foi ratificada, por meio do Decreto $99.710^{6}$, a Convenção sobre os Direitos da Criança, a qual, apesar de só ter sido incorporada ao ordenamento jurídico brasileiro no ano citado, foi aprovada pela Assembleia Geral da ONU em 1989, influenciando, de forma significativa, as disposições contidas no Estatuto da Criança e do Adolescente (ECA). Os ensinamentos de Sposato corroboram esse pensamento:

A mudança de paradigma e a introdução de um novo direito da criança e do adolescente no ordenamento brasileiro encontra suas origens na ratificação da Convenção internacional das Nações Unidas sobre os direitos da criança em 1989, na campanha criança e constituinte e logo na entrada em vigor da própria Constituição (SPOSATO, 2010, p. 47, apud MENEZES; NOGUEIRA JUNIOR, p. 02).

Sendo assim, a Convenção sobre os Direitos da Criança, juntamente com a Constituição de 1988 e o ECA, consagra o princípio que será o ponto principal de discussão neste artigo: o melhor interesse da criança.

\footnotetext{
${ }^{6}$ A Convenção Internacional dos Direitos das Crianças foi aprovada pelo Congresso Nacional por força do art. 49, I, da CF/88: "Art. 49. É da competência exclusiva do Congresso Nacional:

I - resolver definitivamente sobre tratados, acordos ou atos internacionais que acarretem encargos ou compromissos gravosos ao patrimônio nacional; [...]" (BRASIL, 1988).
} 


\section{O PRINCÍPIO DO MELHOR INTERESSE DA CRIANÇA}

O princípio do melhor interesse da criança determina que os menores de dezoito anos devam ser tratados com absoluta prioridade em relação aos adultos, além de serem atendidas suas reais necessidades. Segundo Colucci (2014, p. 29), essa proteção especial almejada pelo princípio do melhor interesse se justifica pela condição peculiar da criança e do adolescente, para garantir que estes possam ter um bom desenvolvimento e transformarem-se em adultos capazes de exercerem sua função na sociedade.

De acordo com ensinamentos de Pereira (2000, p. 216-217), a origem desse princípio guarda relação com o parens patriae, instituto utilizado na Inglaterra para proteger as pessoas que não podiam fazê-lo por conta própria e que, a partir do século XVIII, passou a distinguir entre a proteção infantil e a proteção dos maiores incapazes.

O artigo 3 do Decreto 99.710/90, o qual ratificou a Convenção sobre os Direitos da Criança (PEREIRA, 2000, p. 215), dispõe que:

Todas as ações relativas às crianças, levadas a efeito por instituições públicas ou privadas de bem estar social, tribunais, autoridades administrativas ou órgãos legislativos, devem considerar, primordialmente, o interesse maior da criança (BRASIL, 1990a).

Emprega-se a expressão melhor interesse da criança, "considerando-se o conteúdo da convenção, assim como a orientação constitucional e infraconstitucional adotada pelo sistema jurídico brasileiro" (PEREIRA, 2000, p. 216), além de levar em conta seu aspecto qualitativo (melhor em lugar de maior). De qualquer forma, "o que se deve colocar em primeiro lugar tanto na implementação de políticas públicas quanto na sua execução é o interesse da infância e da juventude, seja ele o 'melhor interesse' seja ele o 'maior interesse'" (COLUCCI, 2014, p. 26).

Logo, por meio desse princípio, tem-se que as decisões judiciais, bem como a aplicação de políticas públicas, entre outras situações nas quais se discuta o desenvolvimento da criança e do adolescente, devem ser pautadas na real necessidade do menor, isto é, no que lhe é mais benéfico, independentemente de influências 
externas $^{7}$. Amin reforça esse entendimento, trazendo interessante posicionamento crítico:

Trata-se de princípio orientador tanto para o legislador como para o aplicador, determinando a primazia das necessidades da criança e do adolescente como critério de interpretação da lei, deslinde de conflitos, ou mesmo para elaboração de futuras regras.

Assim, na análise do caso concreto, acima de todas as circunstâncias fáticas e jurídicas, deve pairar o princípio do melhor interesse, como garantidor do respeito aos direitos fundamentais titularizados por crianças e jovens.

Infelizmente, nem sempre a prática corresponde ao objetivo legal. Não raro, profissionais, principalmente da área da infância e juventude, esquecem-se que o destinatário final da doutrina protetiva é a criança e o adolescente e não "o pai, a mãe, os avós, tios etc." (AMIN, 2010, p. 12).

Segundo Barboza, "pode-se afirmar que, antes mesmo da Constituição Federal de 1988, o princípio do melhor interesse da criança, como orientador da solução dos conflitos envolvendo menores, estava consagrado" (BARBOZA, 2000, p. 205, grifo da autora), o que demonstra que, ainda que não houvesse previsão legislativa adequada, o entendimento da área era de que as necessidades das crianças e adolescentes deveriam ser tidas como prioritárias. Nesse sentido, Amin (2010, p. 30) observa que esse princípio já se encontrava presente no Código de Menores de 1979, em seu art. $5^{0}{ }^{8}$, contudo, só era aplicado aos menores em situação irregular, visto que tal diploma só se referia a crianças e adolescentes nessa condição.

Diante do princípio do melhor interesse da criança, diversas situações que envolvem menores ganham novos contornos e interpretações. Por exemplo, na adoção, o que se busca é garantir o direito do adotado a uma família, e não o direito dos adotantes à adoção. Isso torna ainda mais revoltante a situação do sistema de adoção brasileiro, que, além de apresentar extrema morosidade no procedimento de adoção, permite que o adotante escolha as características do adotado, ferindo o princípio do melhor interesse. No mesmo sentido, posicionam-se Anastácio e Orselli:

Permitir a seleção do adotando de acordo com os desejos do pretendente faz surgir, ainda, a segregação de crianças e adolescentes. [...]

\footnotetext{
${ }^{7}$ Nesses casos, faz-se necessária a atuação de uma equipe multidisciplinar que procure aferir o que é o melhor para a criança na situação concreta. O Estatuto da Criança e do Adolescente traz a exigência da equipe multidisciplinar em seu art. 19, $\S 1^{\circ}$ (em caso de acolhimento familiar ou institucional), no art. 157, $\S 1^{\circ}$ (em caso de procedimento para perda ou suspensão do poder familiar), entre outros.

8 "Art. $5^{\circ} \mathrm{Na}$ aplicação desta Lei, a proteção aos interesses do menor sobrelevará qualquer outro bem ou interesse juridicamente tutelado" (BRASIL, 1979).
} 
Além de atentar contra a dignidade humana do adotando, a possibilidade de selecionar suas características físicas implica a segunda causa de demora no trâmite da adoção. Consequência que se reflete drasticamente na vida da criança e do adolescente, porquanto os obriga a permanecer muito tempo, ou até mesmo toda sua menoridade, dentro de uma instituição. Crescem sob os cuidados impessoais de uma equipe profissional e sem conhecer aquilo que a Constituição Federal assegura no artigo 227, o direito à convivência familiar (ANASTẢCIO; ORSELLI, 2010, p. 08).

Dessa forma, fica evidente a importância do princípio do melhor interesse da criança para o ramo do Direito da Criança e do Adolescente. Apesar de, como observa Pereira (2000, p. 226), ser difícil identificar tal princípio na interpretação das normas que tratam sobre a criança e o adolescente, é possível perceber uma grande evolução no que diz respeito à legislação brasileira.

\subsection{Da aplicação do princípio na legislação brasileira}

A partir da revolução representada pela Constituição Federal de 1988 no tratamento do direito da criança e do adolescente, o ordenamento jurídico brasileiro tem sido atualizado com diversos dispositivos que, claramente, colocam em prática o princípio do melhor interesse da criança, buscando sempre beneficiar a situação dos menores de dezoito anos.

Um importante exemplo de dispositivo legal que põe em prática o princípio do melhor interesse da criança é a questão da licença-maternidade, a qual já era prevista antes mesmo da Constituição de 1988. O artigo 392 (com redação dada pela Lei no 10.421/02) da Consolidação das Leis do Trabalho (CLT) dispõe que "a empregada gestante tem direito à licença-maternidade de 120 (cento e vinte) dias, sem prejuízo do emprego e do salário"9 (BRASIL, 1943). Do mesmo modo, o artigo 207 da Lei oㅡ $8.112 / 90^{10}$ determina que "será concedida licença à servidora gestante por 120 (cento e vinte) dias consecutivos, sem prejuízo da remuneração" (BRASIL, 1990b). Dessa forma,

\footnotetext{
${ }^{9}$ Esse benefício também é garantido pela Constituição Federal, em seu art. $7^{\circ}$, XVIII:

"Art. $7^{\circ}$ São direitos dos trabalhadores urbanos e rurais, além de outros que visem à melhoria de sua condição social: I/XVII - [...]; XVIII - licença à gestante, sem prejuízo do emprego e do salário, com a duração de cento e vinte dias; [...]" (BRASIL, 1988).

${ }^{10}$ Lei que "dispõe sobre o regime jurídico dos servidores públicos civis da União, das autarquias e das fundações públicas federais” (BRASIL, 1990b).
} 
o recém-nascido pode ficar sob os cuidados da mãe, sem que esta tenha prejuízos ou sofra retaliações em sua situação profissional.

Esse benefício tanto é concedido em prol da criança, que também existe previsão legal para casos de adoção e obtenção de guarda judicial (CLT, art. 392-A; Lei no 8.112/90, art. 210), tendo como finalidade conferir ao menor um período de adaptação à nova família.

Outro ponto interessante é o art. 209, da Lei no 8.112/90, que garante o descanso da servidora para fins de amamentação. De acordo com o Ministério da Saúde,

Amamentar é muito mais do que nutrir a criança. É um processo que envolve interação profunda entre mãe e filho, com repercussões no estado nutricional da criança, em sua habilidade de se defender de infecções, em sua fisiologia e no seu desenvolvimento cognitivo e emocional, e em sua saúde no longo prazo [...] (BRASIL, 2015, p. 11).

Sendo assim, vê-se que a legislação preza pela saúde do recém-nascido, sendo possível verificar o incentivo ao aleitamento materno tanto no Estatuto da Criança e do Adolescente, em seu art. 9º, quanto na Constituição Federal, que garante, em seu art. $5^{\circ}$, L, condições para que as presidiárias amamentem seus filhos.

Romar aponta mais um avanço no que diz respeito às mães trabalhadoras:

A Lei n. 11.770/2008 ampliou a licença-maternidade de 120 para 180 dias, beneficiando primeiro o funcionalismo público federal (Programa Empresa Cidadã). No caso da iniciativa privada, a medida começou a valer efetivamente apenas a partir de janeiro de 2010, prevendo incentivo fiscal para as empresas que aderirem à prorrogação da licença-maternidade de 120 para 180 dias (ROMAR, 2018, p. 782, grifo da autora).

Desse modo, com a ampliação do período da licença-maternidade, percebe-se que o legislador busca proteger, ainda mais, a criança recém-nascida, potencializando as melhorias trazidas por esse benefício e priorizando o desenvolvimento do bebê em seus primeiros meses de vida.

Ainda nessa seara, tem-se a Lei no 13.363/16, que altera o Estatuto da Advocacia e da Ordem dos Advogados do Brasil e o Código de Processo Civil (CPC) "para estipular direitos e garantias para a advogada gestante, lactante, adotante ou que der à luz e para o advogado que se tornar pai” (BRASIL, 2016b). Tais direitos 
compreendem, inclusive, a possibilidade de suspensão do processo nos termos do art. 313 do CPC, cujos incisos IX e X foram incluídos pela supracitada lei:

Art. 313. Suspende-se o processo:

$\mathrm{I} / \mathrm{VIII}-[\ldots]$;

IX - pelo parto ou pela concessão de adoção, quando a advogada responsável pelo processo constituir a única patrona da causa;

$X$ - quando o advogado responsável pelo processo constituir o único patrono da causa e tornar-se pai (BRASIL, 2015).

Esses dispositivos demonstram o compromisso do legislador em garantir que a criança não seja prejudicada pelo fato de seus pais exercerem profissões fora de casa, assegurando que estes se abstenham do serviço, nos momentos adequados, para dirigir cuidados aos menores.

Passando para a esfera criminal, também se encontram disposições que visam à proteção da criança e do adolescente. A Lei $\mathrm{n}$ ำ13.721/18 acrescenta um parágrafo único ao artigo 158 do Código de Processo Penal (CPP), de modo que:

Art. 158. [...]

Parágrafo único. Dar-se-á prioridade à realização do exame de corpo de delito quando se tratar de crime que envolva:

I- $[\ldots]$;

II - violência contra criança, adolescente, idoso ou pessoa com deficiência (BRASIL, 1941).

Isso mostra a atenção do legislador com a apuração de crimes contra a criança e o adolescente. Tal preocupação também pode ser constatada por meio do artigo 225 do Estatuto da Criança e do Adolescente, o qual define serem de ação pública incondicionada os crimes contidos no ECA, revelando a gravidade dos delitos cometidos contra os menores.

Outro dispositivo que deve ser citado é a Lei $n^{0} 13.257 / 16$, que "dispõe sobre as políticas públicas para a primeira infância" (BRASIL, 2016a) e altera uma série de leis, como o Código de Processo Penal e o próprio Estatuto da Criança e do Adolescente. Dar-se-á destaque ao Código de Processo Penal.

A partir da Lei no 13.257/16, tornou-se obrigatória, assim como verificado no art. 6º X do CPP, a coleta de informações "sobre a existência de filhos, respectivas idades e se possuem alguma deficiência e o nome e o contato de eventual responsável pelos cuidados dos filhos, indicado pela pessoa presa" (BRASIL, 1941) pela autoridade 
policial, logo que tiver conhecimento da prática da infração penal, durante o interrogatório (CPP, art. 185, § 10) e em caso de prisão em flagrante (CPP, art. 304, § $\left.4^{\circ}\right)$.

A Lei $n^{0} 13.257 / 16$ também acrescentou três incisos ao art. 318 do CPP, que passou a vigorar com a seguinte redação:

Art. 318. Poderá o juiz substituir a prisão preventiva pela domiciliar quando o agente for:

$\mathrm{I} / \mathrm{III}-[\ldots]$;

IV - gestante;

$V$ - mulher com filho de até 12 (doze) anos de idade incompletos;

$\mathrm{VI}$ - homem, caso seja o único responsável pelos cuidados do filho de até 12 (doze) anos de idade incompletos (BRASIL, 1941).

A redação anterior previa a possibilidade da substituição da prisão preventiva por prisão domiciliar no caso de gestante a partir do sétimo mês de gravidez ou se esta fosse de alto risco, de modo que a alteração evidencia a preocupação do legislador com a saúde do bebê em todos os estágios da gestação.

Quanto aos incisos $\mathrm{V}$ e $\mathrm{VI}$, fica claro que o objetivo é resguardar o melhor interesse da criança, por meio dos cuidados que esta receberá, garantindo sua proteção integral. Importante citar que o inciso III do mesmo artigo já previa tal substituição em caso de agente "imprescindível aos cuidados especiais de pessoa menor de 6 (seis) anos de idade ou com deficiência" (BRASIL, 1941), de acordo com a redação dada pela Lei no 12.403/11.

Mais um dispositivo que merece destaque é a Lei ㄲo 13.431/17, que, regulamentada pelo Decreto oㅜ 9.603/18, "estabelece o sistema de garantia de direitos da criança e do adolescente vítima ou testemunha de violência" (BRASIL, 2017). Essa legislação visa a proteger o menor que sofreu violência física, psicológica, sexual ou institucional (art. 4ํㅜ da Lei ํㅜ 13.431/17), evitando sua revitimização e respeitando os princípios da proteção integral e do melhor interesse da criança (art. $2^{\circ}$ do Decreto ํo 9.603/18).

Já quando se trata do Direito de Família, deve ser citada a questão da guarda. O instituto da guarda compartilhada, inserido no Código Civil (CC) por meio da Lei no $11.698 / 08$ e regulamentado pela Lei $n^{\circ} 13.058 / 14$, surgiu para garantir que os filhos 
possam se desenvolver com a presença do pai e da mãe. Desse modo, o Código Civil passa a incentivar a guarda compartilhada, conforme disposto em seu art. 1.584, § 2을

Quando não houver acordo entre a mãe e o pai quanto à guarda do filho, encontrando-se ambos os genitores aptos a exercer o poder familiar, será aplicada a guarda compartilhada, salvo se um dos genitores declarar ao magistrado que não deseja a guarda do menor (BRASIL, 2002).

É certo que, caso as condições não sejam favoráveis à concessão da guarda compartilhada (como, por exemplo, se não houver um mínimo de cumplicidade entre os genitores, ou, conforme disposto no CC, se o pai ou mãe declarar que não deseja a guarda do filho), deverá ser instituída a guarda unilateral ao pai ou à mãe, lembrando que, nessas situações, "há de se notar que há três interesses envolvidos: os do pai, os da mãe, e os da criança. Nesses casos, são os interesses da criança que devem ser analisados e sopesados no momento de se deferir a guarda a este ou aquele genitor" (COLUCCI, 2014, p. 123).

Também existe a possibilidade prevista pelo art. 1.584, $\S 5^{\circ}$ do Código Civil, 0 qual dispõe que

se o juiz verificar que o filho não deve permanecer sob a guarda do pai ou da mãe, deferirá a guarda a pessoa que revele compatibilidade com a natureza da medida, considerados, de preferência, o grau de parentesco e as relações de afinidade e afetividade (BRASIL, 2002).

Segundo Gonçalves (2017, p. 374-375), tem sido aceita até mesmo a guarda compartilhada de um dos genitores com terceira pessoa, como, por exemplo, a avó ou tia da criança.

Todas essas regras visam, é claro, à proteção do menor, consoante observado pelo emprego, em todo o texto do Código Civil, de expressões como "sempre tendo em vista as condições fáticas e os interesses dos filhos" (BRASIL, 2002), no art. 1.583, § 2ㅇ; "em atenção a necessidades específicas do filho" (BRASIL, 2002), no art. 1.584, II; "observados os interesses da criança ou do adolescente" (BRASIL, 2002), no art. 1.589, parágrafo único, entre outros.

Interessante notar a mudança trazida por essas disposições em contraposição à Lei do Divórcio (Lei n 6.515/77), a qual, em seu art. 10, definia que "na separação judicial fundada [...], os filhos menores ficarão com o cônjuge que a ela não houver 
dado causa" (BRASIL, 1977). Essa determinação não mais prevalece, visto que, além de não mais ser discutida a culpa na separação ou no divórcio, o Código Civil dispõe que a questão da guarda deve ser decidida levando em conta as necessidades e interesses dos menores. Nesse mesmo sentido, observa Gonçalves, citando o princípio do melhor interesse da criança e a Convenção sobre os Direitos da Criança:

Não se indaga, portanto, quem deu causa à separação e quem é o cônjuge inocente, mas qual deles revela melhores condições para exercer a guarda dos filhos menores, cujos interesses foram colocados em primeiro plano. [...] A regra inovadora amolda-se ao princípio do "melhor interesse da criança", identificado como direito fundamental na Constituição Federal (art. $5^{\circ}$, $\S 2^{\circ}$ ), em razão da ratificação pela Convenção Internacional sobre os Direitos da Criança-ONU/89 (GONÇALVES, 2017, p. 365).

Desse modo, vê-se como o Direito da Criança e do Adolescente foi capaz de causar mudanças em outros ramos do Direito, buscando a aplicação dos princípios citados ao longo do texto.

\section{CONSIDERAÇÕES FINAIS}

Diante do exposto e a partir de atividade hermenêutica coordenada entre as disposições da Constituição Federal de 1988 e as normas infraconstitucionais apresentadas - ensejando genuíno diálogo entre tais fontes - foi possível realizar uma interpretação sistemática do ordenamento jurídico brasileiro e concluir pela relevância do princípio estudado.

Torna-se, pois, evidente que o melhor interesse da criança é um dos princípios basilares do Direito da Criança e do Adolescente. Analisando o ordenamento é perceptível a relevante evolução obtida, visto que se passou de um Código de Menores extremamente omisso em relação aos direitos - e que concentrava seus esforços na medida da internação -, para leis que reforçam e complementam o caráter de proteção integral apresentado pelo Estatuto da Criança e do Adolescente.

O próximo passo é buscar a aplicação efetiva dessas disposições para que essas leis, de natureza ímpar, não permaneçam apenas no plano da simbologia. Também se deve atentar para a possibilidade de retrocessos, como, por exemplo, as disposições da Reforma Trabalhista sobre o trabalho insalubre da gestante. Essa 
precarização da situação da trabalhadora - que, consequentemente, afeta a saúde do bebê - apresentada como "flexibilização" da norma trabalhista claramente não se enquadra na harmonia evidenciada pela supracitada coordenação entre as disposições constitucionais e a legislação que leva em conta o princípio da proteção integral, prejudicando os avanços apresentados neste trabalho.

Ademais, é preciso exigir a atuação dos conselhos municipais, estaduais e nacional dos direitos da criança e do adolescente, os quais são previstos pelo ECA e possuem a importante função de assegurar a proteção dos menores de dezoito anos. A participação e o acompanhamento da população nas atividades desses conselhos são fundamentais, visto que contribuem para a garantia dos direitos em destaque. Nesse mesmo sentido, é importante incentivar, também, a atuação do Ministério Público (assim como previsto pela Lei ํㅜ 8.069/90), não só como fiscal da lei, mas também como defensor dos direitos individuais, difusos e coletivos das crianças e dos adolescentes.

Sendo assim, faz-se necessário lutar contra os retrocessos e buscar a efetiva aplicação dos princípios em questão, ressaltando a importância dos órgãos citados. A legislação brasileira já evoluiu muito no que diz respeito aos direitos dos menores de dezoito anos e espera-se que essa evolução avance ainda mais.

\section{REFERÊNCIAS}

AMIN, Andréa Rodrigues. Princípios Orientadores do Direito da Criança e do Adolescente. In: MACIEL, Kátia (Coord.). Curso de Direito da Criança e do Adolescente: Aspectos Teóricos e Práticos. 4. ed. rev. e atual. Rio de Janeiro: Editora Lumen Juris, 2010. p. 19-30.

ANASTÁCIO, Andressa; ORSELLI, Helena de Azeredo. Adoção: a Possibilidade de Escolha das Características do Adotando no Processo de Adoção - Análise a Partir dos Fundamentos Constitucionais. Publicado na Revista Brasileira de Direito das Famílias e Sucessões. Edição de dezembro/janeiro de 2010, ano XI, n. 13, pela Editora Magister em parceria com o IBDFAM (Instituto Brasileiro de Direito de Família).

Disponível em: <http://pasquali.adv.br/public/uploads/downloads/adocao.pdf>. Acesso em: 01 mar. 2019.

BARBOZA, Heloísa Helena. O princípio do melhor interesse da criança e do adolescente. O princípio do melhor interesse da criança: da teoria à prática. In: A família 
na travessia do milênio. Anais do Il Congresso Brasileiro de Direito de Família. Belo Horizonte: Del Rey, 2000. p. 201-213.

BRASIL. Constituição (1988). Constituição da República Federativa do Brasil. Brasília: Senado, 1988.

. Decreto no 99.710, de 21 de novembro de 1990. Disponível em:

<http://www.planalto.gov.br/ccivil_03/decreto/1990-1994/d99710.htm>. Acesso em: 10 out. 2018. (a)

. Decreto-Lei no 3.689, de 3 de outubro de 1941. Disponível em:

<http://www.planalto.gov.br/ccivil_03/decreto-lei/Del3689.htm>. Acesso em: 11 out. 2018.

. Decreto-Lei no 5.452, de $1^{\circ}$ de maio de 1943. Disponível em: <http://www.planalto.gov.br/ccivil_03/Decreto-Lei/Del5452.htm>. Acesso em: 11 out. 2018.

. Lei no 4.513, de 1ํ de dezembro de 1964. Disponível em: <http://www.planalto.gov.br/ccivil_03/LEIS/1950-1969/L4513.htm>. Acesso em: 28 mar. 2019.

. Lei no 6.515, de 26 de dezembro de 1977. Disponível em: <http://www.planalto.gov.br/ccivil_03/leis/L6515.htm>. Acesso em: 28 fev. 2019.

. Lei no 6.697, de 10 de outubro de 1979. Disponível em: <http://www.planalto.gov.br/ccivil_03/Leis/1970-1979/L6697.htm>. Acesso em: 27 fev. 2019.

. Lei no 8.112, de 11 de dezembro de 1990. Disponível em: <http://www.planalto.gov.br/ccivil_03/LEIS/L8112cons.htm>. Acesso em: 11 out. 2018. (b)

. Lei no 10.406, de 10 de janeiro de 2002. Disponível em: <http://www.planalto.gov.br/ccivil_03/LEIS/2002/L10406.htm>. Acesso em: 28 fev. 2019.

. Lei no 13.105, de 16 de março de 2015. Disponível em: <http://www.planalto.gov.br/ccivil_03/_Ato2015-2018/2015/Lei/L13105.htm>. Acesso em: 13 out. 2018.

. Lei no 13.257, de 8 de março de 2016. Disponível em: <http://www.planalto.gov.br/ccivil_03/_Ato2015-2018/2016/Lei/L13257.htm>. Acesso em: 02 abr. 2019. (a)

. Lei no 13.363, de 25 de novembro de 2016. Disponível em: <http://www.planalto.gov.br/ccivil_03/_Ato2015-2018/2016/Lei/L13363.htm>. Acesso em: 13 out. 2018. (b) 
. Lei no 13.431, de 4 de abril de 2017. Disponível em:

<http://www.planalto.gov.br/ccivil_03/_Ato2015-2018/2017/Lei/L13431.htm>. Acesso em: 27 fev. 2019.

. Ministério da Saúde. Secretaria de Atenção à Saúde. Departamento de Atenção Básica. Saúde da criança: aleitamento materno e alimentação complementar. 2. ed. Brasília: Ministério da Saúde, 2015.

COLUCCI, Camila Fernanda Pinsinato. Princípio do melhor interesse da criança: construção teórica e aplicação prática no direito brasileiro. Dissertação (Mestrado em Direito Civil) - Faculdade de Direito da Universidade de São Paulo. São Paulo. 2014.

GONÇALVES, Carlos Roberto. Direito civil brasileiro, volume 6: direito de família. 14. ed. São Paulo: Saraiva, 2017.

LIMA, Fernanda da Silva; VERONESE, Josiane Rose Petry. Os direitos da criança e do adolescente: a necessária efetivação dos direitos fundamentais. Florianópolis: Fundação Boiteux, 2012.

MENEZES, Rita de Cássia Barros de; NOGUEIRA JUNIOR, Gabriel Ribeiro. A aplicabilidade do princípio do melhor interesse da criança em decisões de reconhecimento da pluriparentalidade. Disponível em:

<http://www.publicadireito.com.br/artigos/?cod=91a0ac7c34ea63ff $>$. Acesso em: 28 mar. 2019.

$\mathrm{NUCCl}$, Guilherme de Souza. Estatuto da criança e do adolescente comentado: Em busca da Constituição da República Federativa das Crianças e dos Adolescentes do Brasil. Rio de Janeiro: Forense, 2014.

PEREIRA, Tânia da Silva. O princípio do melhor interesse da criança: da teoria à prática. In: A família na travessia do milênio. Anais do II Congresso Brasileiro de Direito de Família. Belo Horizonte: Del Rey, 2000. p. 215-234.

ROMAR, Carla Teresa Martins. Direito do trabalho. 5. ed. São Paulo: Saraiva Educação, 2018.

SILVEIRA, Jessica Ziegler de Andrade. A proteção integral e o melhor interesse da criança e do adolescente: uma abordagem à luz da lei n. 8.069/90. Trabalho de Conclusão de Curso (Bacharelado em Direito) - Universidade Federal do Estado do Rio de Janeiro. Rio de Janeiro. 2015. 